\title{
Editorial
}

\section{Shifting paradigms}

Journal of Revenue and Pricing Management (2009) 8, 403-404. doi:10.1057/rpm.2009.33

Germany and France are out of recession, where as the United Kingdom is seeing the first signs of recovery in 2009. China and India's GDP will grow between 6 and 8 per cent this year, but the United States is still stuck in the mud. During a recession many capacity-constrained businesses have felt the pinch, but those that have survived have known their business. Today, pricing transparency for both consumers and competitors is the norm, with Internet sites such as www.bing.com advising consumers when is the right time to purchase and as a consequence the models of Revenue Management and Pricing are changing. This issue of the Journal of Revenue \& Pricing Management sheds light on some of the strategies, models and tools that have evolved in the past 12 months.

The practice paper section starts with a article by Charles Dimier and colleagues examining how the economic crisis has effected the hotel sector and what levers are at managers' disposal to stem falling RevPar decreases. Most of these are to be found through a better use of pricing, as untapped opportunities remain in rate optimisation, customer loyalty schemes and bundling. Larry Michaels and Steve Fletcher provide an insight into the way in which Low Cost Carriers price their product and revenue manage their flights questioning the validity of the conventional airline revenue management theory and practice. The article concludes with a consideration of all the marketing levers (product, price, promotion and distribution) in an integrated way.

Professor Sameer Kumar and colleagues attempt to look at trends in the marketplace of some of the major components of variable cost and their effects on total product cost and revenues by outsourcing of consumer products manufacturing in China from a strategic manufacturing perspective. Four major cost component trend are discussed; the rate of rising wages in the United States and in China; material cost (specifically steel); the costs of shipping goods from China to the United States; and the risk of profit loss owing to recalls, quality issues, loss or damage of goods and/or potential loss of customers.

The research papers sections starts with an interesting proposition by Dr Hasan Arslan and colleagues on the issue of the timing of new product introductions and pricing of multiple product generations. They analyse the case where Revenue Management manages multiple generations of a product, and where demand of each generation is impacted by the prices of all existing generations and the introduction of new generations.

Guillaume Roels and Kristin Fridgeirsdottir propose a dynamic optimisation model to maximise a web publisher's online display advertising revenues. The model dynamically selects which advertising requests to accept and dynamically delivers the promised advertising impressions to viewers so as to maximise revenue, accounting for uncertainty in advertising requests and website traffic. These results highlight the importance of accounting for the opportunity cost of capacity allocation in advertisement contract negotiation for globally maximising online publishers' revenues.

Two futures papers are included in the issue, Scott Nason mediates with the subject of a la carte pricing, why nothing is free anymore whether it is checked bags, food, seat reservations, blankets and pillows, headsets and so on. Whereas Tom Walker discusses 
how hotels that discount more aggressively than their competitors achieve a comparative occupancy premium, but that the increase does not offset the room rate sacrifice, eroding RevPAR compared to its competitors. I reviewed Thomas Davenport and Jean Harris book Competing on Analytics: The New Science of
Winning. It is a book that conveys why analysis and analytics are important in the world of the long tail.

Ian Yeoman Victoria University of Wellington New Zealand 